University of Windsor

Scholarship at UWindsor

\title{
Investigating sources and sinks of N2O expression from freshwater microbial communities in urban watershed sediments
}

C. Weisener

J. Lee

S. R. Chaganti

T. Reid

N. Falk

See next page for additional authors

Follow this and additional works at: https://scholar.uwindsor.ca/biologypub

Part of the Biology Commons

\section{Recommended Citation}

Weisener, C.; Lee, J.; Chaganti, S. R.; Reid, T.; Falk, N.; and Drouillard, Ken G., "Investigating sources and sinks of N2O expression from freshwater microbial communities in urban watershed sediments" (2017). Chemosphere, 188, 697-705.

https://scholar.uwindsor.ca/biologypub/742

This Article is brought to you for free and open access by the Department of Biological Sciences at Scholarship at UWindsor. It has been accepted for inclusion in Biological Sciences Publications by an authorized administrator of Scholarship at UWindsor. For more information, please contact scholarship@uwindsor.ca. 


\section{Authors}

C. Weisener, J. Lee, S. R. Chaganti, T. Reid, N. Falk, and Ken G. Drouillard 


\section{Accepted Manuscript}

Investigating sources and sinks of $\mathrm{N}_{2} \mathrm{O}$ expression from freshwater microbial communities in urban watershed sediments

Christopher Weisener, Jumin Lee, Subba Rao Chaganti, Thomas Reid, Nick Falk, Ken Drouillard

PII: S0045-6535(17)31450-9

DOI: 10.1016/j.chemosphere.2017.09.036

Reference: CHEM 19907

To appear in: $\quad E C S N$

Received Date: 28 June 2017

Revised Date: 6 September 2017

Accepted Date: 9 September 2017

Please cite this article as: Weisener, C., Lee, J., Chaganti, S.R., Reid, T., Falk, N., Drouillard, K., Investigating sources and sinks of $\mathrm{N}_{2} \mathrm{O}$ expression from freshwater microbial communities in urban watershed sediments, Chemosphere (2017), doi: 10.1016/j.chemosphere.2017.09.036.

This is a PDF file of an unedited manuscript that has been accepted for publication. As a service to our customers we are providing this early version of the manuscript. The manuscript will undergo copyediting, typesetting, and review of the resulting proof before it is published in its final form. Please note that during the production process errors may be discovered which could affect the content, and all legal disclaimers that apply to the journal pertain. 


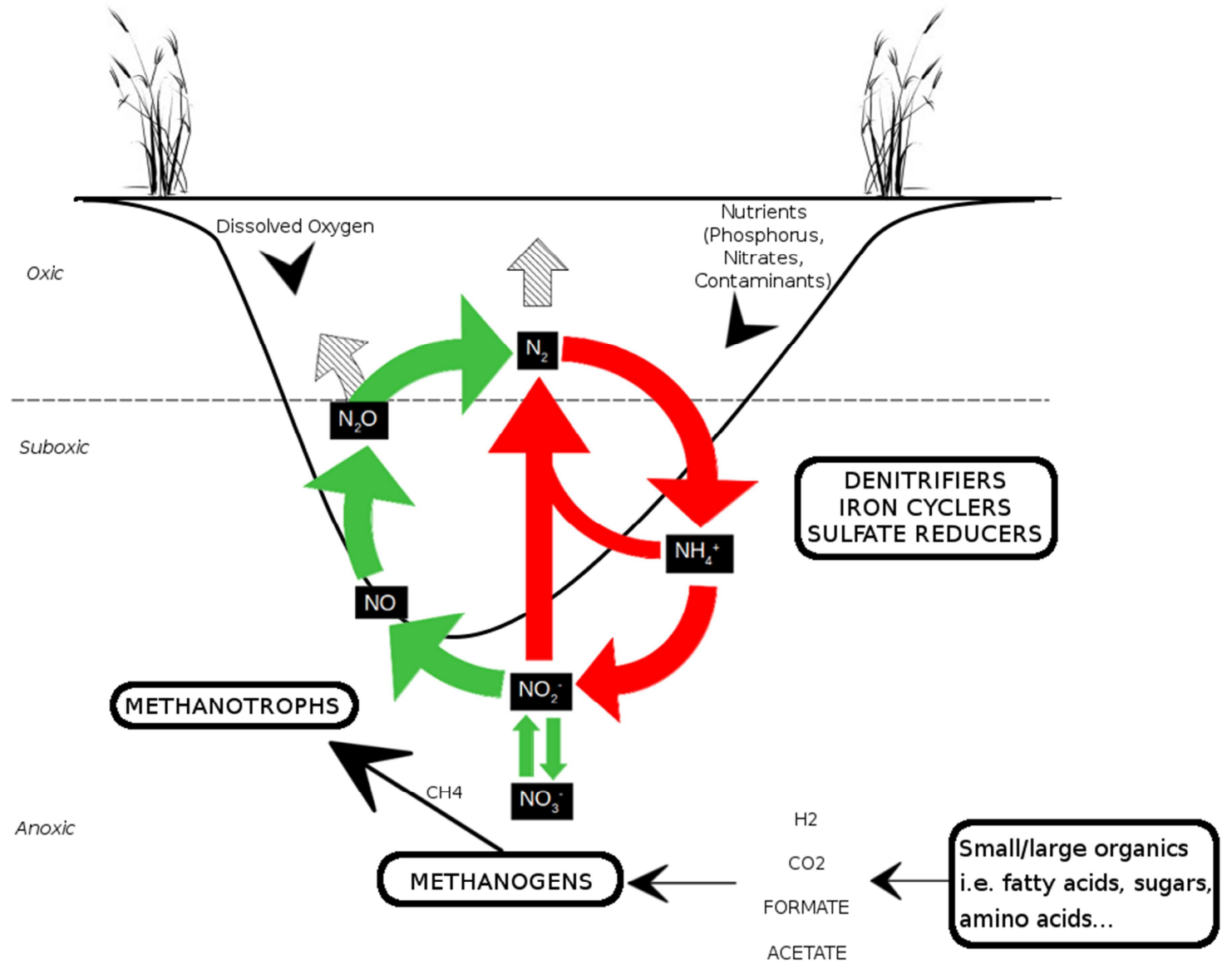


Investigating Sources and Sinks of $\mathrm{N}_{2} \mathrm{O}$ Expression from Freshwater Microbial Communities in Urban Watershed Sediments

Christopher Weisener $^{1 *}$, Jumin Lee ${ }^{1,2}$, Subba Rao Chaganti ${ }^{l}$, Thomas Reid ${ }^{l}$, Nick Falk ${ }^{l}$, Ken Drouillard $^{1}$

${ }^{1}$ Great Lakes Institute for Environmental Science - University of Windsor, 401 Sunset Avenue, Windsor, Ontario, Canada, N9B 3P4

${ }^{2}$ Earth Science Department, Western University, London, Ontario, Canada

*Corresponding Author: weisener@uwindsor.ca; 519-253-3000 ext.3753 


\begin{abstract}
Wastewater treatment plants (WWTPs) serve as point-source inputs for a variety of nutrients often dominated by nitrogenous compounds as a result of anthropogenic influence. These effluents can

impact biogeochemical cycles in freshwater estuaries, influencing microbial communities in both the water and sediment compartments. To assess the impact of point source nutrients, a transect of sediment and pore water samples were collected from 4 locations in the Little River Subwatershed including locations above and below the Little River Pollution Control Plant (LRPCP). Variation in chemistry and microbial community/gene expression revealed significant influences of the effluent discharge on the adjacent sediments. Phosphorus and sulfur showed high concentrations within plume sediments compared to the reference sediments while nitrate concentrations were low. Increased abundance of denitrifiers Dechloromonas, Dok59 and Thermomonas correlating with increased expression of nitrous-oxide reductase suggests a conversion of $\mathrm{N}_{2} \mathrm{O}$ to $\mathrm{N}_{2}$ within the LRPCP effluent sediments. This study provides valuable insight into the gene regulation of microbes involved in $\mathrm{N}$ metabolism (denitrification, nitrification, and nitrite reduction to ammonia) within the sediment compartment influenced by wastewater effluent.
\end{abstract}

\title{
1.0 Introduction
}

Anthropogenic influences on the global nitrogen cycle have created an imbalance to the natural processes by which nitrogen is cycled through the atmosphere, hydrosphere, lithosphere and even biosphere. The extensive use of fertilizers in agricultural practises and human waste disposal has loaded our waterways with nitrogenous compounds affecting the overall ecosystem health and productivity. The microbial consortium within aquatic environments are left to deal with the stresses of enhanced nutrient loads, and largely govern the fate of nitrogen in the subsurface. Rivers and streams serve an important function in both lotic and lentic nitrogen cycling, by acting as conduits for the turnover of the various nitrogenous compounds. The bacteria in these environments provide substantial contributions to both energy flow and the 
transformation of elemental nutrients such as nitrogen and phosphorous (Loick and Weisener, 2014). Their ability to adapt rapidly to changing environments through recombination events and induced mutations, alongside their ability to acquire or exchange genes via horizontal gene transfer (HGT) enables them to adapt readily in any environment (Pontes et al., 2007; Zeigler 2003; Cohan 2001). Within this context nutrient suspension in aquatic systems can have profound impacts on their general productivity. A broad range of microorganisms contribute to nitrogen cycling through a series of metabolic pathways. From a sediment compartment perspective, the denitrification pathway would involve a complete enzymatic reduction to $\mathrm{N}_{2}$, involving the genes nar/nap $\left(\mathrm{NO}_{3}{ }^{-}\right.$to $\left.\mathrm{NO}_{2}{ }^{-}\right)$, nir $\left(\mathrm{NO}_{2}{ }^{-}\right.$to $\left.\mathrm{NO}\right)$, nor $\left(\mathrm{NO}\right.$ to $\left.\mathrm{N}_{2} \mathrm{O}\right)$ and $\operatorname{nos}\left(\mathrm{N}_{2} \mathrm{O}\right.$ to $\mathrm{N}_{2}$ ). Whereas complete denitrification results in the production of $\mathrm{N}_{2}$, incomplete reactions can result in the (unwanted) production of $\mathrm{N}_{2} \mathrm{O}$ (Sanford et al. 2012). Other reactions control the degree of mineralized ammonification which can serve as a potential sediment sink for these nutrients. Indirect abiotic factors also include iron cycling bacteria which have been linked to the production of $\mathrm{Fe}(\mathrm{II}) / \mathrm{Fe}(\mathrm{III})$, which in turn reacts strongly with nitrite contributing to the production of $\mathrm{N}_{2} \mathrm{O}$ (Coby and Picardal, 2005; Cooper et al., 2003; Rakshit et al., 2008). The overall regulation of the nos $Z$ gene specifically, is perhaps most influential in controlling nitrogen emissions from the sediment compartment and its potential impact on atmospheric flux for nitrogen (Sanford et al. 2012).

These mechanisms of nitrogen turnover are particularly important in areas that receive potential point-source impacts from legacy contamination and pollution control facilities (Devarajan et al., 2015). Wastewater treatment plants (WWTP) for example can serve as potential point sources for the release of $\mathrm{N}$ and $\mathrm{P}$ and other emerging contaminants. Most WWTPs include primary (mechanical), secondary (biological), and tertiary (enhanced chemical and/or biological) treatment options that are intended to remove excess organic carbon $(\mathrm{C})$, nitrogen $(\mathrm{N})$ and phosphorus (P) loads prior to release to freshwater tributaries. The utilization of these measures restricts the release of excessive nutrients, which can negatively impact ecosystem water quality. In most cases WWTPs effluents try to meet the regulatory guidelines based off jurisdiction. 
However, increased rainfall events often lead to controlled discharges of inadequately treated wastewater effluents which can impact both the sediment chemistry and microbial deportment (Fauvel et al., 2016). Reduced forms of nitrogen (e.g. ammonia) and total phosphorus loads, along with other chemical compounds may continue to undergo bacterial cycling once released and incorporated into the sediment profile. This has the potential to form geochemical "hotspots" at the sediment-water interface which can influence the microbial community structure along downstream WWTP discharge routes (Palmer-Felgate et al. 2010; Drury et al. 2013). In many cases the sediment compartment remains a "black box" with respect to true microbial functionality within the context of emerging contaminants and controls of nitrogen and phosphorous. Gaining a complete functional understanding of the microbial metabolic activity in both pristine and contaminated watersheds is a necessary venture in monitoring current and future contaminants with respect to public health.

The Detroit River is a fast flow corridor connecting Lake St. Clair and Lake Erie, flowing through both agricultural and densely urbanized regions. The Little River Pollution Control Plant (LRPCP), servicing the municipalities of both Windsor and Tecumseh, Ontario, is in the Little River (LR) sub-watershed and is impacted by both urban and recreational development (e.g., a golf course and marinas). Once dominated by agricultural land-use, the LR sub-watershed is now 46.6\% urban land cover (Bejankiwar, 2009). Opposite to the LR sub-watershed is Peche Island, situated centrally in the Detroit River. The island is isolated from direct urban impact and represents a natural system, isolated from Little River by strong currents and is distal to the pollution control plant. Alternatively, the low flow conditions associated with Little River may be an important hydrological factor contributing to nutrient and contaminant gradients, as well as physical and chemical attributes related to WWTP discharge, thus impacting the microbial consortia (Fono et al., 2006; Drury et al., 2013).

This location provides a unique opportunity to investigate the microbial cycling of nitrogen within the sediment compartment and microbial dynamics associated with a potential nutrient 
point-source and a natural reference site within the same watershed. In this study, we investigate the influence of the LRPCP on microbial diversity and function in sediments along the LR corridor and Peche Island sediments. The up- or downregulation of denitrifying genes within the LRPCP sediment compartment are investigated in addition to other genes involved in nitrogen metabolism. Further the study investigates whether the LRPCP adjacent sediments are behaving as a conservative sink for $\mathrm{N}$ mineralization (i.e. $\mathrm{NH}_{4}$ ) or a potential source for $\mathrm{N}_{2} \mathrm{O}$ or $\mathrm{N}_{2}$ emissions.

\subsection{METHODS}

\subsection{LR Sub-Watershed and LRPCP Geography}

The Little River Sub-Watershed - LRSW (64.9 km²) within the larger Essex Region Watershed ERW (1681 km²) drains via Little River into the Detroit River in Windsor, Ontario, Canada. The LRSW is dominated by a primarily urbanized land use regime (46\% as of 2011), a contrast to the approximately 75\% agricultural use of the rest of the Essex Region Watershed (Essex Region Source Protection Area Annual Assessment, 2015). Flowing north through Windsor, the Little River Pollution Control Plant (LRPCP) was commissioned in 1966, and is situated on the eastern bank of Little River. The LRPCP serves the eastern end of the City of Windsor (Pop. 210,000), as well as the neighboring Town of Tecumseh (Pop. 23 000). With a capacity of $73000 \mathrm{~m}^{3} /$ day, the LRPCP produces some of the highest quality effluent in the province of Ontario (City of Windsor, 2017). The LRPCP is located approximately $1 \mathrm{~km}$ upstream of the confluence of Little River and the Detroit River, where it empties into a marina and then the larger river system. The LR canal is largely surrounded by residential housing lots, with agricultural lands located further upstream.

\subsection{In Situ Water and Sediment Sampling}

Sediment core samples were collected from the Little River Canal (LRC), through to the confluence with Detroit River and the designated reference site Peche Island. In total four locations were selected proximal and distal to the LRPCP (Fig. 1). Two sampling sites near the 
LRPCP were chosen, one at the effluent discharge point (EDP) and one approximately $600 \mathrm{~m}$ upstream (UDP) from the discharge point. A downstream discharge point (DDP) was selected approximately $600 \mathrm{~m}$ from the LRPCP where the LRC empties into the Detroit river. The fourth sample was collected at the reference site, from the Peche Island sediments (RPS), isolated from any direct WWTP influence.

Sediment was collected using a gravity-assisted coring device, using $67 \mathrm{~mm}$ diameter core tubes. For both DNA and RNA sequencing, sediment was collected from the top $2 \mathrm{~cm}$ using sterilized scoopulas, placed into $5 \mathrm{~mL}$ cryotubes, and flash frozen in a liquid nitrogen filled vessel at $-80^{\circ} \mathrm{C}$ (Molecular Dimensions CX-100 Dry Shipper). Once transported to the lab, samples were again stored at $-80^{\circ} \mathrm{C}$ until nucleic acid extractions commenced. The remaining bulk sediment samples were collected in ziplock bags, transported back to the lab and stored in a $4{ }^{\circ} \mathrm{C}$ fridge where porewater chemistry was analyzed within $24 \mathrm{hrs}$. Additionally, a multi-parameter probe was deployed at each sampling location to record water column chemical parameters (sulfur, $\mathrm{pH}$, specific conductivity, magnesium, silicon, dissolved oxygen, salinity, temperature, strontium, phosphorus and nitrate).

\subsection{Pore water Chemistry}

Water chemistry analyses were performed at the Geochemistry-Metals Analysis Lab at the Great Lakes Institute for Environmental Research (GLIER) at the University of Windsor. Representative pore water samples were collected in triplicate from each core interface (e.g. 0 - 4 $\mathrm{cm}$ range per core) using $0.2 \mu \mathrm{m}$ sterile nylon syringe filters (ThermoScientific) to extract the pore water from the bulk sediment. Pore waters were extracted under $\mathrm{N}_{2}$ atmosphere in a confined glove box. Filtered water samples were diluted to a 1:5 ratio in ACS reagent grade nitric acid to a total volume of $10 \mathrm{~mL}$ and stored at $4{ }^{\circ} \mathrm{C}$ until analyzed for trace metals using inductively coupled plasma optical emission spectrometry (Perkin Elmer ICP-OES, and a 700 series Agilent 720-ES ICP-OES system). The ThermoScientific Orion AQ4000 Handheld spectrophotometer was used to measure total nitrate (AC2007), nitrite (AC2046) and 
orthophosphate (AC2095) concentrations.

\subsection{DNA/RNA Extractions and 16s rRNA gene amplicon library construction}

DNA extractions were performed per the manufacturer's instructions of the MoBio PowerSoil DNA isolation kits, except for extracting $5 \mathrm{~g}$ of sediment, opposed to the $2 \mathrm{~g}$ specified in the manual. Four samples were extracted from UDP, EDP, and DDP cores, and three from RPS. Two stages of the PCR reactions (PCR1 and PCR2) were conducted prior to pooling samples for sequencing. PCR1 amplified the V5-V6 region of the 16S rRNA gene using an established primer pair (Table 1), followed by purification, barcoding via PCR2, gel extraction, and quality control measurements following previous protocols (DiLoreto et al., 2016). Pooled samples were diluted to 50-60 ng/ $\mu \mathrm{L}$ and sequenced using the Ion Torrent Personal Genome Machine (Life Technologies) at the GLIER Environmental Genomics Facility.

Total RNA extractions were performed using the MoBio Powersoil Total RNA Isolation Kits per slightly modified protocols. Initial sediment quantity for extraction was increased to $5 \mathrm{~g}$ for improved RNA yield. All reagents and samples were kept on ice throughout extraction to maintain RNA integrity and minimize degradation throughout the extraction. Quality and concentrations were analyzed on an Agilent 2100 Bioanalyzer, with screening for samples with a minimum concentration of $100 \mathrm{ng} / \mu \mathrm{L}$, and quality score of RIN (RNA integrity) \# of 7.5. Samples of sufficient quality and concentration were sent in duplicate to Genome Quebec Innovation Center at McGill University in Montreal, Quebec, Canada. There, samples were sequenced on the Illumina HiSeq 2000 Nextgen sequencer following rRNA-depletion by a RiboZero rRNA removal kit.

\subsection{Bioinformatics for 16S Amplicon Sequencing}

Bioinformatics for amplicon sequencing datasets for quality filtering, OTU picking, and taxonomy assignment were performed using the Quantitative Insights into Microbial Ecology (MacQIIME V. 1.9.1) bioinformatics pipeline (Caporaso et al., 2010). A minimum quality score 
of $\mathrm{Q}=20$ and basepair cutoff of $100 \mathrm{bp}$ was selected for quality assurance. De novo OTU picking was performed to cluster sequences at a 97\% similarity threshold into their representative OTUs using the UCLUST algorithm (Edgar 2010). Chimera check was performed using the Chimera Slayer tool (Haas et al., 2011). Taxonomy was assigned to the clustered OTUs using the RDP classifier at $90 \%$ similarity against the default GreenGenes database. OTUs were averaged within sampling site replicates and expressed as a percent $(\%)$ relative abundance. Within the PAST (PAleontological STatistics; V2.17) program, the Diversity Indices $(\alpha)$ Test was conducted using OTU numbers for all sample sites with Bootstrap N of 9999 (Hammer et al., 2001). Then, Shannon H and Chao 1 Diversity Indices, which characterize species diversity, evenness and richness, were selected to conduct Univariate One-way ANOVA and Tukey's posthoc tests to determine any significant differences $(\mathrm{p}<0.05)$ across the sampled sites. Bray-Curtis dissimilarity was used for the principal coordinate analysis (PCoA) of the top 100 taxa, and the canonical correspondence analysis (CCA) incorporating the measured environmental parameters with these top 100 taxa. Similarity Percentages (SIMPER) assessed dissimilarity between taxa observed at each sample site, and one-way PERMANOVA analyses to determine if the bacterial community composition was significantly different between all sites.

\subsection{Bioinformatics for RNAseq (Metatranscriptomics)}

Raw paired-end RNAseq files were uploaded to the MG-RAST (MetaGenome Rapid Annotation Substem Technology, v3.1) server at the Argonne National Library (http://metagenomics.anl.gov/) (Meyer et al., 2008). Quality control, alignment and annotations are performed in this automated pipeline, for not only RNAseq datasets, but also metagenomic and targeted amplicon studies. The Phred score was set to $\mathrm{Q}=30$ to remove any low-quality reads, and sequence similarity thresholds set to $60 \%$ for functional assignments within MGRAST. Annotation assignments for metabolic functions was performed using the KO (KEGG Orthology) database, and visualizations performed using the KEGG mapper. Exported functional annotations were averaged between replicate samples $(n=2)$ and normalized to the rpoB (DNA-directed RNA Polymerase) gene to allow comparisons between both sample sites. 


\subsection{RESULTS \& DISCUSSION}

\subsection{Pore water Chemistry}

Pore water chemistry was collected from the sediment water interface $(0-4 \mathrm{~cm})$ from each respective core. In each case, significant variation both within the plume and reference environments was observed for the nutrients measured. Samples were analyzed for sulfur $\left(\mathrm{SO}_{4}{ }^{-2}\right)$ and dissolved nutrients $\left(\sum \mathrm{NO}_{3}{ }^{-}\right.$and $\left.\sum \mathrm{PO}_{4}{ }^{-3}\right)$, which served as biochemical markers for the two sediment extremes (plume vs. reference sediments). Sulfur concentrations measured from the sediment water interface varied along the Little River transect. Sulfate concentration in pore water collected from (UDP) location were $12 \mu \mathrm{g} / \mathrm{L}$ compared to $14.7 \mu \mathrm{g} / \mathrm{L}$ and $17.3 \mu \mathrm{g} / \mathrm{L}$ at the effluent discharge (EDP) and the downstream discharge points (DDP) respectively. In this case sulfur concentrations increased in the sediments downstream away from the plume. The Peche Island (RPS) site had the lowest $\mathrm{S}$ concentration at only $5.8 \mu \mathrm{g} / \mathrm{L}$. In contrast, $\mathrm{PO}_{4}{ }^{-3}$ concentrations shown were significantly higher (Tukey's post-hoc test, $\mathrm{p}<0.005$ ) at EDP measuring $553 \mu \mathrm{g} / \mathrm{L}$ compared to UDP, DDP and RPS measurements from $241 \mu \mathrm{g} / \mathrm{L}, 253 \mu \mathrm{g} / \mathrm{L}$ and $274 \mu \mathrm{g} / \mathrm{L}$, respectively. This observation is perhaps not surprising since historically the LRPCP has experienced fluctuating P loads within its wastewater effluent (92-95\% removal efficiency from 2010 to 2015) (City of Windsor, 2015). The oscillating P load in the effluent would likely result in elevated backgrounds of $\mathrm{P}$ in the adjacent sediments compared to distal upstream and downstream locations. Interestingly, average $\mathrm{NO}_{3}^{-}$concentrations were significantly lower (Tukey's post-hoc test, $\mathrm{p}<0.05$ ) in the EDP sediments at $12.5 \mu \mathrm{g} / \mathrm{L}$ compared to UDP, DDP and RPS concentrations of $18 \mu \mathrm{g} / \mathrm{L}, 22 \mu \mathrm{g} / \mathrm{L}$ and $22.5 \mu \mathrm{g} / \mathrm{L}$, respectively. The depression of nitrate in the sampled sediment pore water within the effluent discharge zone may possibly suggest a high nitrate turnover as opposed to low background concentrations. The difference in available nitrate within the different sediment compartments may reflect significant community shifts between microbial nutrient cyclers and the sediments' capacity to act as either a conservable sink or source. This will be further discussed in the following sections relating observed taxa with functional gene expression. 


\subsection{Watershed Microbial Taxonomy \& Diversity}

\subsubsection{S rRNA gene Amplicon Sequencing Statistics}

The amplified V5-V6 region of the bacterial 16S rRNA gene was targeted and processed on samples collected from the 4 sites (UDP, EDP, DDP and RPS). After post-processing (filtering, demultiplexing and trimming) the data averaged 67418 reads per sample. Approximately 8400 OTUs were generated with $97 \%$ cut-off using QIIME. To understand the impact of LRPCP effluent on microbial diversity a Tukey's pairwise test was conducted using Shannon $\mathrm{H}$ and Chao 1 diversity indices as inputs. Shannon index results showed significant difference between UDP and RPS samples $(\mathrm{p}<0.05)$. However, Chao 1 showed that the RPS samples were significantly different from DDP, EDP and UDP ( $p<0.05, \mathrm{p}<0.01$, and $\mathrm{p}<0.01$, respectively). In this study, species diversity (evenness and abundance) in the EDP sediments was higher compared to the RPS sediments. Alternatively, other studies have shown that wastewater effluent or acute contaminant pressures can lower both abundance and diversity of benthic bacterial communities in urban rivers (Ager et al., 2010; Drury, et al. 2013). Some have suggested that rivers chronically exposed to contaminants recover, often to a high species level diversity through the proliferation of more tolerant species (Sun et al., 2013). In some cases, positive correlations have been identified between the nutrient concentrations and increased bacterial numbers within wastewater effluent and benthic sediments (Garnier, 1991; Gucker, et al., 2006). Perhaps, it was not surprising, that in this study the microbial composition within EDP showed a highly diverse community compared to the RPS location, since it is receiving potentially higher loads of nutrients and perhaps other contaminants encouraging diversity of specialists. To further understand the variation among and between sites, a Principal Coordinates Analysis (PCoA) was performed using the 100 abundant OTUs among all sites. PCoA 1 and 2 explained $68 \%$ of the variation (Fig. 2). PCoA plots revealed that the variation among sites was minimal, while there was evident variation between sites (Fig. 2).

\subsubsection{Environmental parameters and Microbial Community Composition Relationships}


The sediment microbiome was then analyzed to begin to interpret the effect of the wastewater effluent on its structure and function. The resulting taxonomy showed that the top ten phyla were dominated by Proteobacteria, Bacteroidetes, Verrucomicrobia, Acidobacteria, Chlorobi, Actinobacteria, Planctomycetes, Spirochaetes, Firmicutes and Chloroflexi (Fig. 3). There was no significant difference in the abundance of Proteobacteria across sites, which was the most dominant ubiquitous bacterial group, detected in all samples. However, at the genus level, the denitrifying bacteria, Dechloromonas ( $\beta$-Proteobacteria), showed 10-fold higher abundance at EDP compared to RPS (Fig. 4). This was an interesting observation since Dechloromonas is known to oxidize organohalides in the presence of nitrate as well as degrade benzene and other polycyclic aromatic hydrocarbons (Meckenstock \& Muttaki, 2011; Chakraborty \& Picardal, 2013). Given the historically high hydrocarbon and organics input into Little River, this could potentially explain the low concentrations of nitrate measured in the pore water of EDP. Other genera identified in EDP include Thermomonas species ( $\gamma$-Proteobacteria) and Dok59 species ( $\beta$-Proteobacteria). The relative abundances of these organisms were significantly higher compared to the RPS location. These heterotrophs are also responsible for denitrification process in sediments and play an important role in removing soluble nitrate and nitrite from the wastewater environments (Ginige, et al., 2005). Leptothrix ( $\beta$-Proteobacteria) was also detected at EDP, a genus capable of oxidizing both iron and manganese in aquatic environments (Emerson \& Weiss, 2004), and are often associated with WWTP environments.

The phylum Verrucomicrobia is a freshwater bacterium (Lemke, et al., 2009), responsible for fixing nitrogen (Khadem, et al., 2010), oxidizing methane (Dunfield, et al., 2007), and is linked to the degradation of a range of polysaccharides (Janssen et al., 1997; Sangwan et al., 2004; Wertz et al., 2011). EDP showed decreased abundance of Verrucomicrobia compared to RPS. Specifically, Chthoniobacter (Verrucomicrobia), an organism known for metabolizing pyruvate, sugars, and sugar polymers in aerobic environments, was found in highest abundance at RPS (Wertz, et al., 2011). The suppression of Chthoniobacter at EDP could be attributed to its inability to grow with nitrate as an electron acceptor and its sensitivity to elevated nutrient loads 
and oxygen depletion (Sangwan, et al., 2004). Geobacter ( $\delta$-Proteobacteria), a diverse heterotrophic degrader and metal cycler associated with natural wetlands (Straub, 2011; Lovley, et al., 1993) was more abundant at RPS than EDP. Its niche in nitrogen cycling may be attributing to its observed suppression at EDP. In summary, the relative abundances of Chthoniobacter and Geobacter were statistically lower at the plume, suggesting that these species may be sensitive to the effluent chemistry and sediment condition.

To correlate geochemical conditions and the microbial community compositions within the sampling sites, a canonical correspondence analysis (CCA) was conducted. The CCA included 12 different environmental parameters measured in situ at the time of sampling and included the top 100 abundant OTUs (Fig. 5). Turbidity and dissolved oxygen were correlated positively with RPS, while salinity and specific conductivity were negatively correlated. EDP showed a strong correlation with temperature, sulfur and phosphorus, while $\mathrm{pH}$ and nitrate were negatively correlated. Each component of CCA was assessed using Eigen and p values. Thus, CCA1 was statistically significant with an eigenvalue of 0.7936 and p value of 0.002 and CCA2 was lower with an eigenvalue of 0.2085 and $p$ value of 0.014 , both at 999 permutations. SIMPER analysis was performed to confirm existing correlations between the environmental parameters and bacterial community compositions. The SIMPER analysis showed dissimilarity between EDP, DDP and RPS ranged from 70-77\%. This result confirms that variations in microbial community structure across the sites are in part controlled by spatial proximity to the LRPCP. To correlate observed taxa to nutrient-specific biogeochemical function within the sediment, metatranscriptomics analyses were used to reveal in situ microbial gene expression between each of the chosen sediment sites. For these analyses, EDP and RPS were chosen based on the observed chemical and taxa dissimilarity, representing two local environmental extremes with respect to anthropogenic influence from the Little River Pollution Control Plant.

\subsection{Microbial Gene Expression}

\subsubsection{RNAseq Statistics \& Functional Assignments}


Peche Island (RPS) metatranscriptome datasets had an averaged post QC sequence count of 17 717 046, mean sequence lengths of 117 basepairs, and 673079 annotated identified functional categories, with the effluent discharge point (EDP) containing 11231974,117 basepairs, 481 721 , and 379143 , respectively. For functional interpretation, gene hits were normalized to the number of hits of the DNA-directed RNA polymerase beta subunit $(r p o B)$. This was done by dividing the number of hits of a given gene by the number of hits of the conserved rpoB gene, yielding the presented abundance percentage values. Observed abundances of key functional genes involved in prokaryotic nitrogen, methane, and sulfur cycling pathways were correlated and shown in Figure 6.

\subsubsection{Nitrogen Metabolism}

In many cases, bacterial-mediated transformations can alter the bioavailability of nitrogen species, potentially enhancing or limiting the potential for nutrient-driven eutrophication and anoxia of the water column. Thus, the question is asked are the sediments serving as a potential sink or source for nutrient resuspension (e.g. ammonia or nitrate). Investigations into active transcripts associated with nitrogen metabolism are key to understanding site-specific nutrient dynamics and ecosystem health. Nitrogen transcripts associated with RPS and EDP constituted $1.5 \%$ and $2.5 \%$ of their respective transcriptomes. In this case nitrate reduction, particularly dominated via the denitrification pathway, was observed and was highly expressed at the EDP site $(91.1 \%$ of the nitrogen metabolism annotated transcripts). Denitrification within EDP sediments followed a stepwise conversion of $\mathrm{NO}_{3}{ }^{-}$to $\mathrm{N}_{2}$ by a series of $\mathrm{N}$-reductases including periplasmic nitrate reductase (napA), nitrite reductase (nir), nitric oxide reductase (nor), and finally nitrous-oxide reductase (nosZ). Transcripts for all four enzymes showed significantly higher abundance at the EDP vs. RPS sediments (napA: $\mathrm{p}<0.001$, nir: $\mathrm{p}<0.005$, nor: $\mathrm{p}<0.005$, nos: $\mathrm{p}<0.005$ ) inferring a higher sediment nitrate reduction potential (Fig. 7). This pathway can buffer the effects of anthropogenic $\mathrm{N}_{2} \mathrm{O}$ inputs by liberating nitrogen from the sediments as $\mathrm{N}_{2}$ (Papaspyrou et al., 2014). However, the increase in nos $Z$ expression in the EDP sediments is significant suggesting that an active pool of $\mathrm{N}_{2} \mathrm{O}$ exists. In addition to the expression of nor (NO 
to $\mathrm{N}_{2} \mathrm{O}$ ), two competing reactions could be providing additional nitrous oxide inputs within the EDP sediment. The abundance of Leptothrix in the EDP sediment indirectly suggests that an active ferrous iron pool may be available. The presence of Fe (II) will control abiotic production of $\mathrm{N}_{2} \mathrm{O}$ enhancing its availability for increased expression of the nos $Z$ pathway (Rakshit et al. 2008; Sandford et al. 2012). Other mechanistic contributors for the $\mathrm{N}_{2} \mathrm{O}$ pool within the EDP sediment may also be derived from methanogenic activity in this carbon rich environment (Kits et al. 2015). Methanotrophs have the capability of producing $\mathrm{N}_{2} \mathrm{O}$ directly from available $\mathrm{NO}_{2}{ }^{-}$ and $\mathrm{NO}_{3}{ }^{-}$as a sole source of nitrogen (Hoefman et al. 2014).

In general, the rapid consumption of nitrate by denitrifying bacteria within the EDP sediments is also reflected in the observed low nitrate concentrations in the pore water at this location (12.5 $\mu \mathrm{g} / \mathrm{L})$ compared to the other sampling areas $(18 \mu \mathrm{g} / \mathrm{L}, 22.5 \mu \mathrm{g} / \mathrm{L}$, and $22.3 \mu \mathrm{g} / \mathrm{L}$ for the EDP, DDP, and RPS respectively). Elevated gene expression of cysteine and methionine metabolism ( $m e t H, m e t K$, and $a h c Y$ ) was also observed and is likely linked to the dominant denitrification, sulfur and methanogenic activity within the EDP sediments. The first enzymatic step of denitrification (nitrate to nitrite) within the EDP sediment is driven by periplasmic nitrate reductase (nap: $64.6 \%$ abundance) in contrast to a membrane-bound nitrate reductase (nar: $0.18 \%$ abundance). This finding was also surprising, as nar is generally favored over nap in anaerobic settings. However, nap has been found to be preferentially expressed in relatively low nitrate, oxygen-depleted environments, such as those characterized by typical WWTP effluent (Dong et al., 2009; Potter et al., 1999). Thus, the lower pore water nitrate concentration at EDP may be driving nap expression via denitrifying bacteria such as Dechloromonas, providing a selective advantage to this genus that can harness $\mathrm{N}$-scavenging pathways for energy conservation. Denitrifying Dechloromonas, Dok59, and Thermomonas constitute the dominant bacterial genera detected at EDP, and therefore could be benefiting from this enzymatic trade off (Coates et al., 2001; Ginige et al., 2005; Li et al., 2016; Mergaert et al., 2003).

Although not dominant, genes were also identified that were involved in dissimilatory nitrate 
reduction to ammonium (DNRA). This ammonia-generating pathway, showed relatively low abundance within the EDP sediments $(0.99 \%$ abundance for $n r f C$ and $1.26 \%$ abundance for $n r f D$ ) suggesting a limited capacity for nitrogen mineralization. Nitrogen fixation transcripts also showed low expression, therefore $\mathrm{N}_{2}$ generated through denitrification was not being cycled back to ammonia. These observations further confirmed that sediments proximal to the LRPCP were not a site of bioavailable N-replenishment. In contrast within the RPS sediments, DNRA and Nfixation transcripts were also in low abundance. However, nitrification transcripts, specifically those involved in ammonia-oxidation, showed increased abundance compared to EDP and may be more reflective of a healthy wetland ecosystem. Ammonia monooxygenase (amo) and hydroxylamine oxidoreductase (hao) genes contribute to the conversion from ammonium to nitrate and had abundance values of $47 \%$ and $4.5 \%$, respectively, in the RPS sediments, compared to $22.5 \%$ and $1.7 \%$ in the EDP sediments. Higher expression of amo in the RPS sediment was likely due to comparably higher dissolved oxygen in the Detroit River setting, therefore favoring ammonia-oxidation. However, $a m o B$ was still active in the EDP sediments possibly reflecting small pools of available DO. Even in this case, the presence of oxygen would not entirely limit denitrification, as simultaneous $\mathrm{O}_{2}$ and $\mathrm{NO}_{3}{ }^{-}$use has recently been observed in sediments (Marchant et al., 2017). The co-expression of ammonia, nitrogen and sulfur pathways in these sediment locations is likely reflective of discrete redox environments at or below the sediment-water interface. The EDP sediments exhibit high sulfate concentrations and the potential for dissolved sulfide species in the absence of oxygen, based on high $d s r A B$ expression. Depending on the situation, this could have an inhibitory effect on both aerobic and anaerobic ammonia oxidation, and in some cases, may be responsible for reducing the potential for nitrification in the EDP sediments (Joye et al., 1995; Martens-Habbena et al., 2009). The suppression of anammox gene transcripts ( $h z o$ and $h z s)$ and lack of representative genera (Van Niftrik and Jetten, 2013) observed in EDP sediments suggests that there is likely an inhibitory process, possibly competition between ongoing methanogenic activity or sulfur reduction (Jin et al., 2013). Additionally, potential BOD and P loads to the EDP sediments from the effluent may also act as inhibiting factors for the anammox process. However, beyond direct microbial 
competition, there could simply be toxic inhibition resulting from alcohols, phenols and even antibiotics present in the LRPCP sediment (Jin et al., 2012).

\subsection{CONCLUSIONS}

The effluent from the Little River Pollution Control Plant (LRPCP) has a significant influence on sediments within its discharge location. Differences in chemistry and biological function were clearly observed comparing both the Peche Island reference location and LRPCP sediments. This included significant changes in sediment microbial diversity, dominated by active denitrification metabolism in the LRPCP discharge location. The dominance of denitrification vs. nitrification pathways within the EDP sediment suggest that this point source environment is not behaving as a net source or sink for ammonia but rather a conduit for $\mathrm{N}_{2}$ gas release. Highly expressed nos $Z$ compared to other denitrification genes indicates a sizeable pool of $\mathrm{N}_{2} \mathrm{O}$ available for release into the water column or for reduction to $\mathrm{N}_{2}$. Aside from a direct denitrification pathway contributing to the $\mathrm{N}_{2} \mathrm{O}$ flux, observed syntrophic and cooperative metabolism from Fe-cyclers and methane and ammonia oxidizers are actively involved. This study has shown the advantage of implementing a multi-gene approach to enhance the understanding of the overall microbial metabolism in anthropogenic impacted sediments. Future studies will directly correlate nitrogen speciation with this gene expression to identify possible gene biomarkers indicative of wastewater treatment effluents, or other anthropogenic inputs.

\section{ACKNOWLEDGEMENTS}

We thank the Great Lakes Institute for Environmental Research (GLIER) for access to field equipment logistics and support from the environmental genomics facility (EGF) and Metals laboratory. Research was funded through grants from Natural Sciences and Engineering Council of Canada (NSERC) Discovery program, grant 86006. We also thank collaborative reviewers for their constructive comments throughout the process of creating this manuscript.

\section{CONFLICTS OF INTEREST}


The authors declare no conflicts of interest for any research contained within this manuscript.

\section{REFERENCES}

Ager, D. et al., (2010) Anthropogenic disturbance affects the structure of bacterial communities. Environ Microbiol, Volume 12, pp. 670-678.

Battin, T. J., Luyssaert, S., Kaplan, L. A., Aufdenkampe, A. K., Richter, A., \& Tranvik, L. J. (2009) The boundless carbon cycle. Nature Geoscience, 2(9), 598-600.

Bejankiwar, R., (2009) Water Quality Status Report, Windsor: Essex Region Conservation Authority.

Bell, K. Y., Wells, M. J., Traexler, K. A., Pellegrin, M. L., Morse, A., \& Bandy, J. (2011)

Emerging pollutants. Water Environment Research, 83(10), 1906-1984.

Caporaso, J. G., Kuczynski, J., Stombaugh, J., Bittinger, K., Bushman, F. D., Costello, E. K., ... \& Huttley, G. A. (2010) QIIME allows analysis of high-throughput community sequencing data. Nature methods, 7(5), 335-336.

Chakraborty, A. \& Picardal, F., (2013) Neutrophilic, nitrate-dependent, Fe(II) oxidation by a Dechloromonas species. World J Microbiol Biotechnol, Volume 29, pp. 617-623.

City of Windsor (2015) Quality of Wastewater Indicator.

http://www.citywindsor.ca/residents/environment/Environmental-Master-Plan/Goal-A-ImproveOur-Air-and-Water-Quality/Pages/Quality-of-Wastewater-Indicator.aspx

City of Windsor (2017). Little River Pollution Control Plant.

http://www.citywindsor.ca/residents/environment/Pollution-Control/Laboratory/Pages/Little-

River-Pollution-Control-Plant.aspx

Coates, J. D., Chakraborty, R., Lack, J. G., O'connor, S. M., Cole, K. A., Bender, K. S., \& Achenbach, L. A. (2001) Anaerobic benzene oxidation coupled to nitrate reduction in pure culture by two strains of Dechloromonas. Nature, 411(6841), 1039-1043.

Coby, A. J., \& Picardal, F. W. (2005) Inhibition of NO3- and NO2- reduction by microbial Fe (III) reduction: Evidence of a reaction between NO2- and cell surface-bound $\mathrm{Fe} 2+$. Applied and environmental microbiology, 71(9), 5267-5274. 
Cohan, F. M. (2001) Bacterial species and speciation. Systematic biology, 50(4), 513-524.

Cooper, D. C., Picardal, F. W., Schimmelmann, A., \& Coby, A. J. (2003) Chemical and biological interactions during nitrate and goethite reduction by Shewanella putrefaciens 200 . Applied and environmental microbiology, 69(6), 3517-3525.

Devarajan, N. et al., (2015) Accumulation of clinically relevant antibiotic-resistance genes, bacterial load, and metals in freshwater lake sediments in Central Europe. Environmental Science \& Technlogy, 49(11), pp. 6528-6537.

DiLoreto, Z. A., Weber, P. A., Olds, W., Pope, J., Trumm, D., Chaganti, S. R., ... \& Weisener, C. G. (2016) Novel cost effective full scale mussel shell bioreactors for metal removal and acid neutralization. Journal of Environmental Management, 183, 601-612.

Dong, L. F., Smith, C. J., Papaspyrou, S., Stott, A., Osborn, A. M., \& Nedwell, D. B. (2009) Changes in benthic denitrification, nitrate ammonification, and anammox process rates and nitrate and nitrite reductase gene abundances along an estuarine nutrient gradient (the Colne Estuary, United Kingdom). Applied and environmental microbiology, 75(10), 3171-3179.

Drury, B., Rosi-Marshall, E. \& Kelly, J. J., (2013) Wastewater treatment effluent reduces the abundance and diversity of benthic bacterial communities in urban and suburban rivers. Applied and Environmental Microbiology, 79(6), pp. 1897-1905.

Dunfield, P. F. et al., (2007) Methane oxidation by an extremely acidophilic bacterium of the phylum Verrucomicrobia. Nature, 450(879-882).

Edgar, R.C. (2010) Search and clustering orders of magnitude faster than BLAST.

Bioinformatics 26(19), 2460-2461.

Emerson, D. \& Weiss, J. V., (2004) Bacterial iron oxidation in circumneutral freshwater habitats: finding from the field and the laboratory. Geomicrobiology Journal, Volume 21, pp. 405-414.

Essex Region Source Protection Area Annual Assessment (2015) Watershed Characterization, Updated Assessment Report, March

2015.http://essexregionsourcewater.org/downloads/2015/chapter-2-watershedcharacterization.pdf

Fauvel, B., Cauchie, H. M., Gantzer, C., \& Ogorzaly, L. (2016) Contribution of hydrological data to the understanding of the spatio-temporal dynamics of F-specific RNA bacteriophages in river water during rainfall-runoff events. Water research, 94, 328-340.

Fono, L. J., Kolodziej, E. P. \& Sedlak, D. L., (2006) Attenuation of wastewater-derived 
contaminants in an effluent-dominated river. Environmental Science \& Technology, Volume 40, pp. 7257-7262.

Garnier, J., (1991) Bacterioplankton in the Seine River (France): Impact of Parisian urban effluent. Can. J. Microbiol., Volume 38, pp. 56-64.

Ginige, M. P., Keller, J. \& Blackall, L. L., (2005) Investigation of an Acetate-Fed Denitrifying Microbial Community by Stable Isotope Probing, Full-Cycle rRNA Analysis , and Fluorescent In Situ Investigation of an Acetate-Fed Denitrifying Microbial Community by Stable Isotope Probing, Full-Cycle rRNA An. Applied and Environmental Microbiology, 71(12), pp. 86838691.

Gucker, B., Brauns, M. \& Pusch, M. T., (2006) Effects of Wastewater treatment plant discharge on ecosystem structure and function of lowland streams. Journal of the North American Benthological Society, 25(2), pp. 313-329.

Haas, B. J., Gevers, D., Earl, A. M., Feldgarden, M., Ward, D. V., Giannoukos, G., ... \& Methé, B. (2011) Chimeric 16S rRNA sequence formation and detection in Sanger and 454pyrosequenced PCR amplicons. Genome research, 21(3), 494-504.

Hammer, Ø., Harper, D.A.T., and P. D. Ryan, (2001) PAST: Paleontological Statistics Software Package for Education and Data Analysis. Palaeontologia Electronica 4(1): 9.

Janssen P, Schuhmann A, Morschel E, Rainey F. (1997) Novel anaerobic ultramicrobacteria belonging to the Verrucomicrobiales lineage of bacterial descent isolated by dilution culture from anoxic rice paddy soil. Appl. Environ. Microbiol. 63:1382-1388.

Jin, R.C, Yang, G., Yu, J. 2012. The inhibition of the Anammox process: A review. Chemical Engineering Journal, 197, pp.67-79. Available at: http://dx.doi.org/10.1016/j.cej.2012.05.014. Jin, R. C., Yang, G. F., Zhang, Q. Q., Ma, C., Yu, J. J., \& Xing, B. S. (2013) The effect of sulfide inhibition on the ANAMMOX process. Water research, 47(3), 1459-1469.

Joye, S. B., \& Hollibaugh, J. T. (1995) Influence of sulfide inhibition of nitrification on nitrogen regeneration in sediments. Science, 270(5236), 623.

Khadem, A. F., Pol, A., Jetten, M. S. M. \& Op den Camp, H. J. M., (2010) Nitrogen fixation by the verrucomicrobial methanotroph 'Methylacidiphilum fumariolicum' SolV. Microbiology, Volume 156, pp. 1052-1059.

Kits, K. D., Klotz, M. G., \& Stein, L. Y. (2015) Methane oxidation coupled to nitrate reduction under hypoxia by the Gammaproteobacterium Methylomonas denitrificans, sp. nov. type strain FJG1. Environmental microbiology, 17(9), 3219-3232.

Lemke, M. J. et al., (2009) Description of freshwater bacterial assemblages from the upper 
Parana River floodpulse system, Brazil. Microbial Ecology, 57(1), pp. 94-103.

Li, X., Sun, S., Badgley, B. D., Sung, S., Zhang, H., \& He, Z. (2016) Nitrogen removal by granular nitritation-anammox in an upflow membrane-aerated biofilm reactor. Water research, 94, 23-31.

Loick, N., \& Weisener, C. (2014) Novel molecular tools to assess microbial activity in contaminated environments. In Geomicrobiology and biogeochemistry (pp. 17-35). Springer Berlin Heidelberg.

Lovley, D. R. et al., (1993) Geobacter metallireducens gen. nov. sp. nov., a microorganism capable of coupling the complete oxidation of organic compounds to the reduction of iron and other metals. Archives of Microbiology, Volume 159, pp. 336-344.

Maphosa, F., de Vos, W. M. \& Smidt, H., (2010) Exploiting the ecogenomics toolbox for environmental diagnostics of organohalide-respiring bacteria. Trends in Biotechnology, Volume 28, pp. 308-316.

Marchant, H. K., Ahmerkamp, S., Lavik, G., Tegetmeyer, H. E., Graf, J., Klatt, J. M., ... \& Kuypers, M. M. (2017). Denitrifying community in coastal sediments performs aerobic and anaerobic respiration simultaneously. The ISME journal. 1-14

Martens-Habbena, W., Berube, P. M., Urakawa, H., José, R., \& Stahl, D. A. (2009) Ammonia oxidation kinetics determine niche separation of nitrifying Archaea and Bacteria. Nature, 461(7266), 976-979.

Meckenstock, R. U. \& Muttaki, H., (2011) Anaerobic degradation of non-substituted aromatic hydrocarbons. Environmental biotechnology, Volume 22, pp. 406-414.

Mergaert, J., Cnockaert, M. C., \& Swings, J. (2003) Thermomonas fusca sp. nov. and Thermomonas brevis sp. nov., two mesophilic species isolated from a denitrification reactor with poly ( $\varepsilon$-caprolactone) plastic granules as fixed bed, and emended description of the genus Thermomonas. International journal of systematic and evolutionary microbiology, 53(6), 19611966.

Meyer, F., Paarmann, D., D'Souza, M., Olson, R., Glass, E. M., Kubal, M., ... \& Wilkening, J. (2008) The metagenomics RAST server-a public resource for the automatic phylogenetic and functional analysis of metagenomes. BMC bioinformatics, 9(1), 386.

Palmer-Felgate, E. J., Mortimer, R. J., Krom, M. D., \& Jarvie, H. P. (2010) Impact of pointsource pollution on phosphorus and nitrogen cycling in stream-bed sediments. Environmental science \& technology, 44(3), 908-914.

Papaspyrou, S., Smith, C. J., Dong, L. F., Whitby, C., Dumbrell, A. J., \& Nedwell, D. B. (2014) 
Nitrate reduction functional genes and nitrate reduction potentials persist in deeper estuarine sediments. Why?. PloS one, 9(4), e94111.

Pontes, D. S., Lima-Bittencourt, C. I., Chartone-Souza, E., \& Nascimento, A. M. A. (2007) Molecular approaches: advantages and artifacts in assessing bacterial diversity. Journal of industrial microbiology \& biotechnology, 34(7), 463-473.

Potter, L. C., Millington, P., Griffiths, L., \& Thomas, G. H. (1999) Competition between Escherichia coli strains expressing either a periplasmic or a membrane-bound nitrate reductase: does Nap confer a selective advantage during nitrate-limited growth?. Biochemical Journal, 344(1), 77-84.

Rakshit, S., Matocha, C. J., \& Coyne, M. S. (2008) Nitrite reduction by siderite. Soil Science Society of America Journal, 72(4), 1070-1077.

Sanford, R. A., Wagner, D. D., Wu, Q., Chee-Sanford, J. C., Thomas, S. H., Cruz-García, C., ... \& Nissen, S. (2012) Unexpected nondenitrifier nitrous oxide reductase gene diversity and abundance in soils. Proceedings of the National Academy of Sciences, 109(48), 19709-19714.

Sangwan P, Chen X, Hugenholtz P, Janssen PH. (2004) Chthoniobacter flavus gen. nov., sp. nov., the first pure-culture representative of subdivision two, Spartobacteria classis nov., of the phylum Verrucomicrobia. Appl. Environ. Microbiol. 70:5875-5881

Straub, K. L., (2011) Geobacter. Encyclopedia of Geobiology, pp. 412-413.

Sun, M. Y., Dafforn, K. A., Johnston, E. L. \& Brown, M. V., (2013) Core sediment bacteria drive community response to anthropogenic contamination over multiple environmental gradients. Environmental Microbiology, 15(9), pp. 2517-2531.

Van Niftrik, L., Jetten, M.S.M., (2012) Anaerobic Ammonium-Oxidizing Bacteria: Unique Microorganisms with Exceptional Properties. Microbiol. Mol. Biol. Rev., 76(3), pp. 585-596.

Wertz, J. T. et al., (2011) Genomic and physiological characterization of the Verrucomicrobia isolate Diplosphaera colitermitum gen. nov., sp. nov., reveals microaerophily adn nitrogen fixation genes. Applied and Environmental Microbiology, 78(5), pp. 1544-1555.

Woodling, J. D. et al., (2006) Intersex and other reproductive disruption of fish in wastewater effluent dominated Colorado streams. Comparative Biochemistry and Physiology Part C: Toxicology \& Pharmacology, 144(1), pp. 10-15.

Zeigler, D. R. (2003) Gene sequences useful for predicting relatedness of whole genomes in bacteria. International journal of systematic and evolutionary microbiology, 53(6), 1893-1900. 


\title{
Investigating Sources and Sinks of $\mathrm{N}_{2} \mathrm{O}$ Expression from Freshwater Microbial Communities in Urban Watershed Sediments
}

\author{
Christopher Weisener $^{1 *}$, Jumin Lee $^{1,2}$, Subba Rao Chaganti ${ }^{l}$, Thomas Reid ${ }^{1}$, Nick Falk ${ }^{l}$, Ken Drouillard ${ }^{l}$
}

\section{FIGURE LEGENDS}

Fig. 1. Location of the Little River Pollution Control Plant, Peche Island, and the sampling sites (DDP $=$ Downstream Discharge Point, RPS $=$ Reference Peche Island Site, EDP = Effluent Discharge Point, UDP = Upstream Discharge Point).

Fig. 2. Principal Coordinates Analysis (PCoA) of microbial data. Ellipses represent sample groupings of each sampled sites (DDP $=$ Downstream Discharge Point (4 samples), RPS = Reference Peche Island Site (3 samples), EDP = Effluent Discharge Point (4 samples), UDP = Upstream Discharge Point (4 samples)).

Fig. 3. Relative abundance of the top ten microbial phylum OTUs across the Little River and Peche Island Sites (DDP = Downstream Discharge Point, RPS $=$ Reference Peche Island Site, EDP $=$ Effluent Discharge Point, UDP = Upstream Discharge Point).

Fig. 4. The 7 genera showing differences among sediment samples within Little River and Peche Island sites. Different letters above the error bars represent significant differences assessed using Tukey's post hoc multiple comparisons $(\mathrm{DDP}=$ Downstream Discharge Point, RPS $=$ Reference Peche Island Site, EDP = Effluent Discharge Point, UDP = Upstream Discharge Point).

Fig. 5. Canonical Correspondence Analysis (CCA) of microbial and geochemical data. Ellipses represent sample groupings of each site (DDP $=$ Downstream Discharge Point, RPS $=$ Reference Peche Island Site, EDP = Effluent Discharge Point, UDP = Upstream Discharge Point).

Fig. 6. Averaged gene expression relative to $r p o B$ for both the reference site and the WWTS plume. Genes are categorized per their dominant metabolic pathway associations. nap (periplasmic nitrate reductase), nir (nitrite reductase), nor (nitric oxide reductase), nos (nitrousoxide reductase), amo (ammonia monooxygenase), hao (hydroxylamine oxidase), $n r f$ (nitrate reductase in DNRA), hzo (hydrazine oxidase), hzs (hydrazine hydrolase), $m c r$ (methyl-coenzyme $\mathrm{M}$ reductase), $m r t$ (tetrahydromethanopterin S-methyltransferase), met (sulfate adenylyltransferase), apr (adenylylsulfate reductase), $d s r$ (dissimilatory sulfite reductase), cys $C$ (adenylylsulfate kinase), $c y s H$ (phosphoadenosine phosphosulfate reductase), cysJ (sulfite reductase (NADPH)), suox (sulfite oxidase).

Fig. 7. Expression (\%) of genes relating to the denitrification and nitrification pathways at both RPS (green) and EDP (blue). All expression is normalized to the rpoB gene. 
Table 1: $16 \mathrm{~S}$ rRNA gene target primers used in PCR cycle. Lower-case areas are the linker zones of the primers. $X X X X$ are representative of barcodes $10-12$ base pairs in length, $P 1$ and $A$ are the lon torrent sequencing primers.

Primer

Set

\begin{tabular}{|c|c|c|c|}
\hline & Set & & Primer Sequence $\left(5^{\prime}-3^{\prime}\right)$ \\
\hline PCR1 & $\begin{array}{l}\text { Bacterial } \\
16 \mathrm{~S} \\
\text { V5/V6 }\end{array}$ & $\begin{array}{l}\text { UniA+V5F } \\
\text { UniB+V6R }\end{array}$ & $\begin{array}{l}\text { acctgcctgccgATTAGATACCCNGGTAG } \\
\text { acgccaccgagcCGACAGCCATGCANCACCT }\end{array}$ \\
\hline PCR2 & & $\begin{array}{l}\mathrm{P} 1+\mathrm{UniB} \\
\mathrm{A}+\mathrm{Barcode}+\mathrm{UniA}\end{array}$ & $\begin{array}{l}\text { CCTCTCTATGGGCAGTCGGTGATacgccaccgagc } \\
\text { CCATCTCATCCCTGCGTGTCTCCGACTCAGXXXXX } \\
\text { XXGATacctgcetgccg }\end{array}$ \\
\hline
\end{tabular}




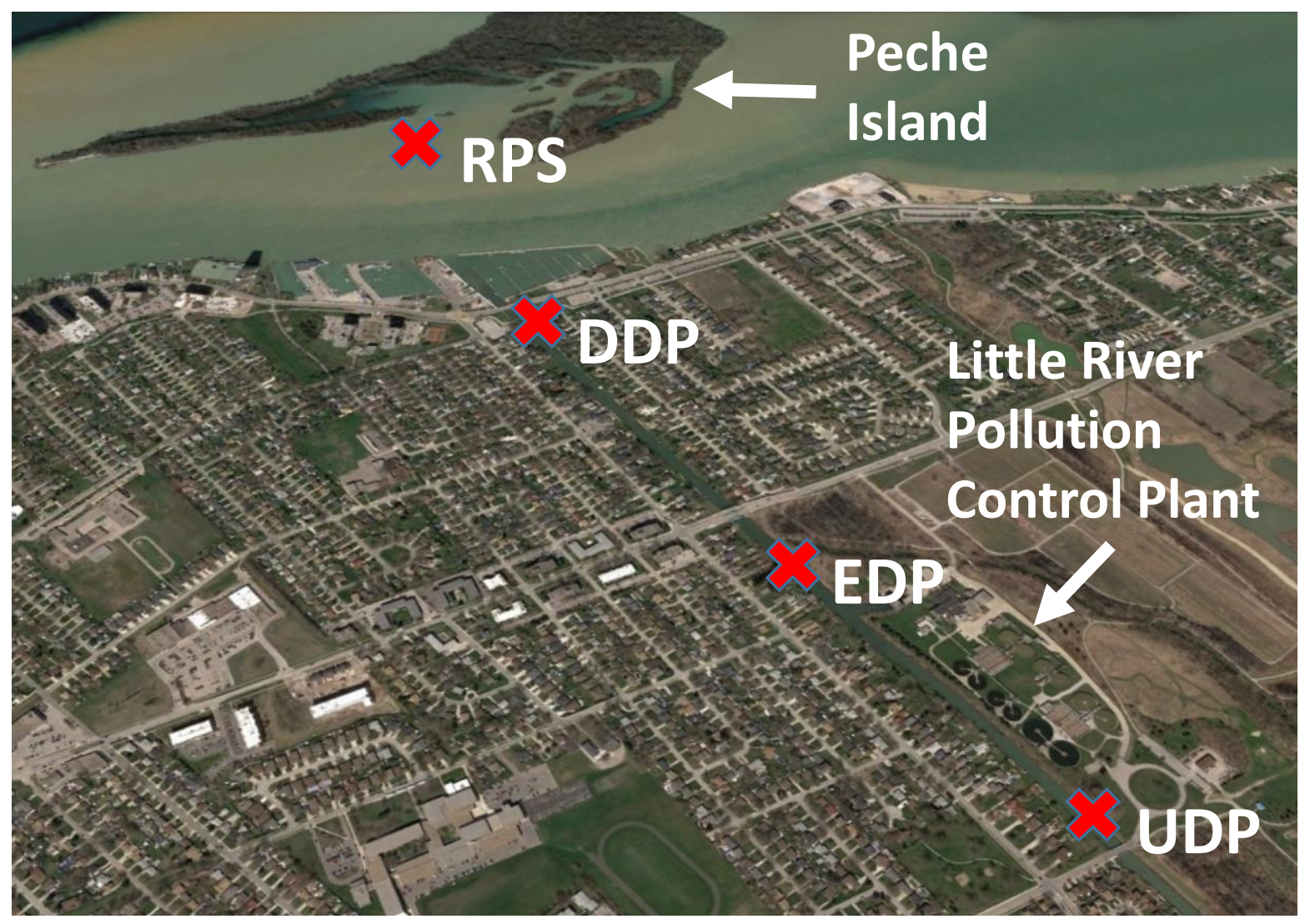




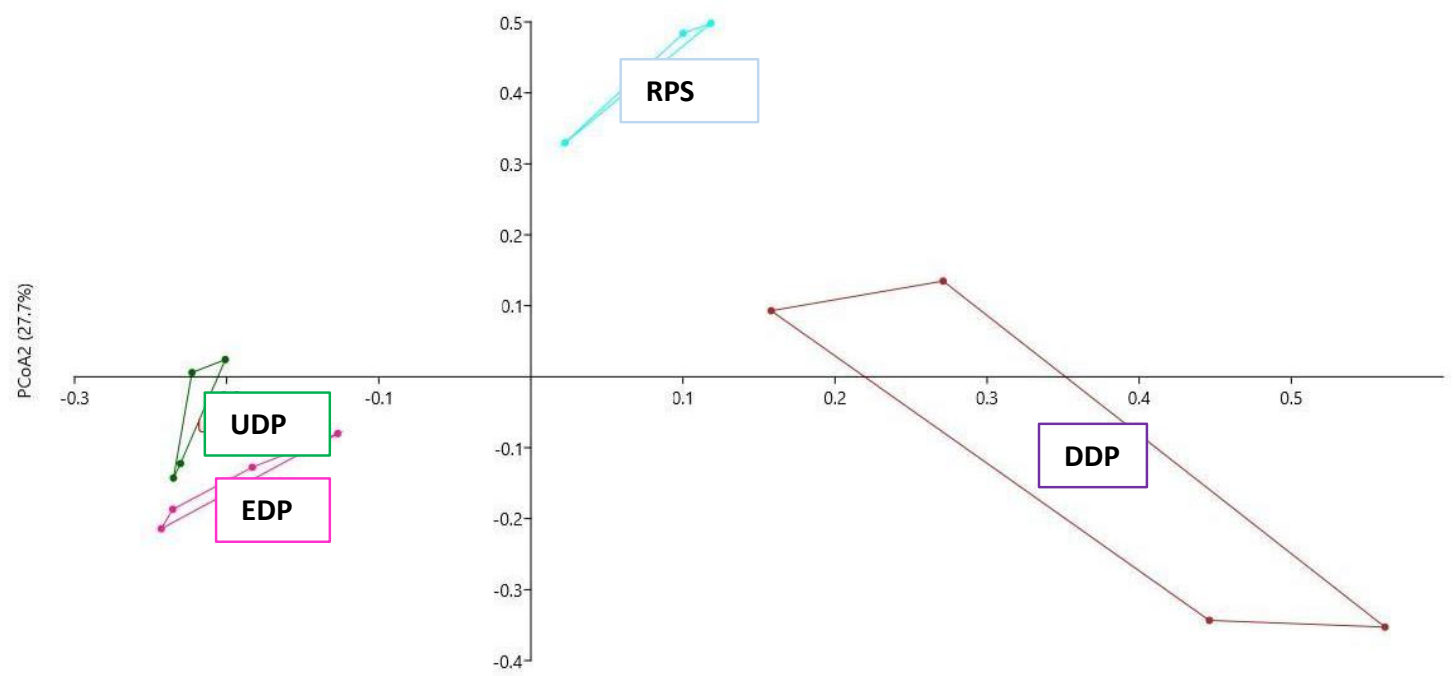

PCoA1 (39.61\%) 


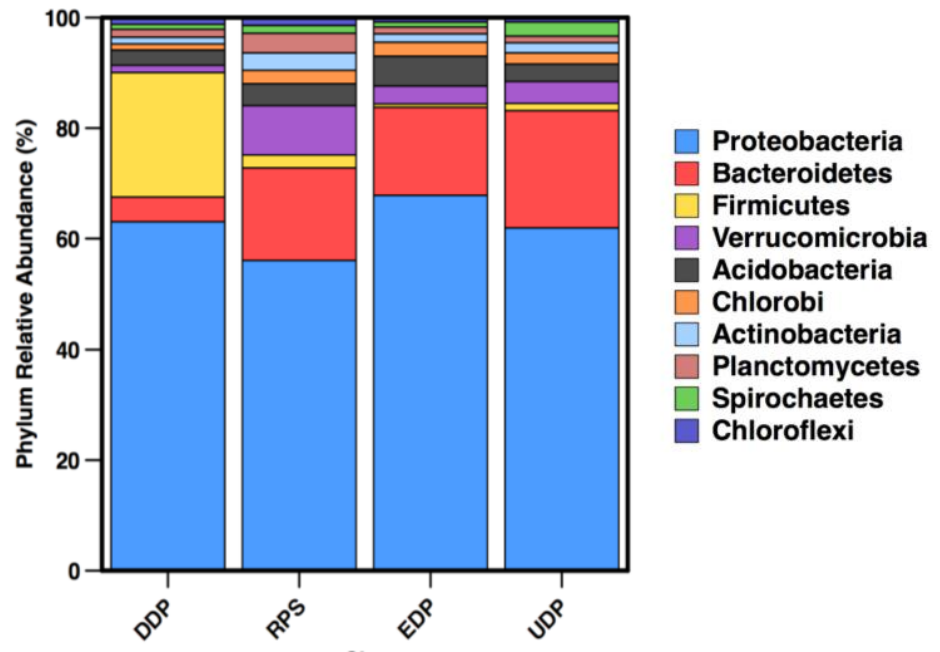



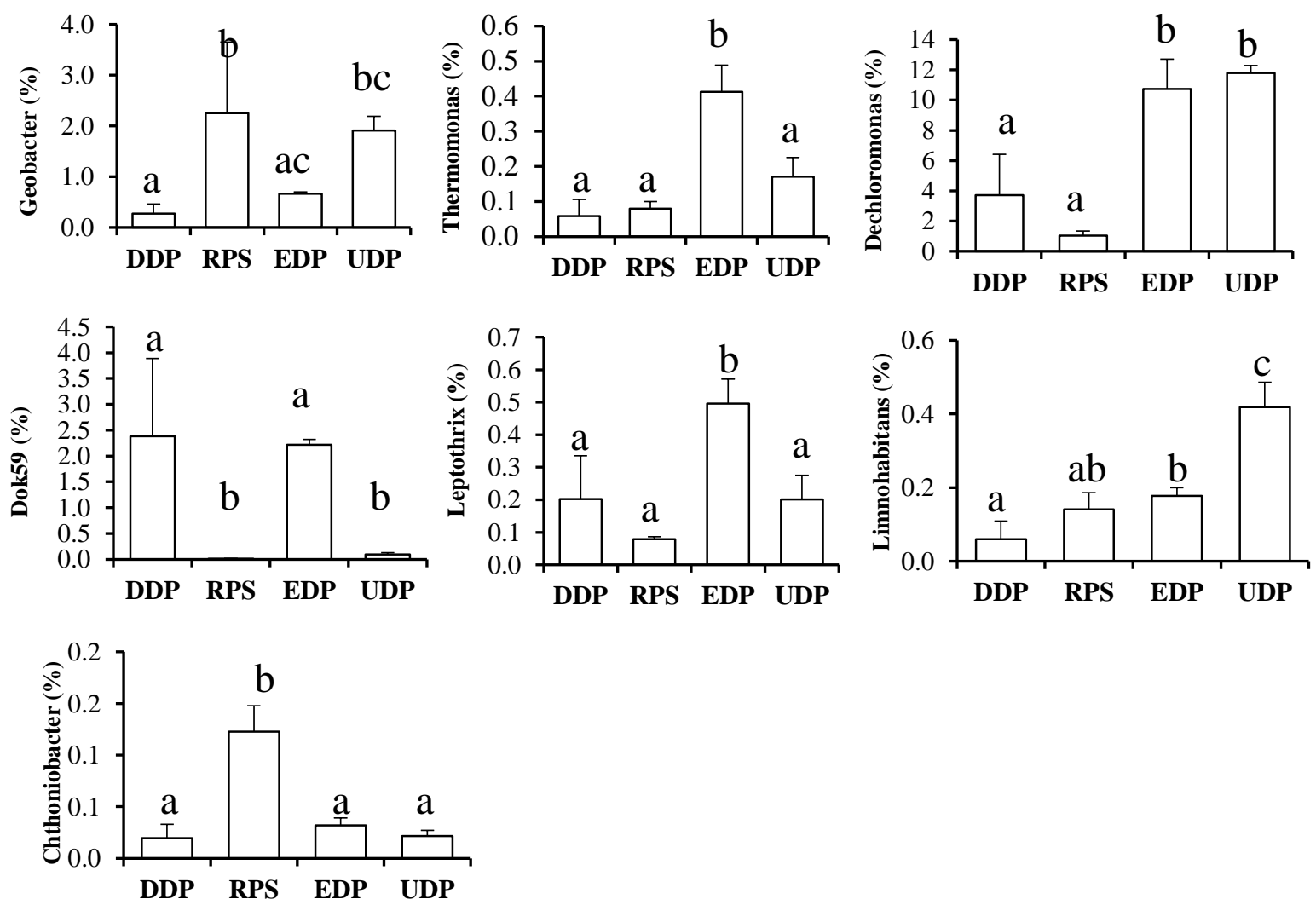


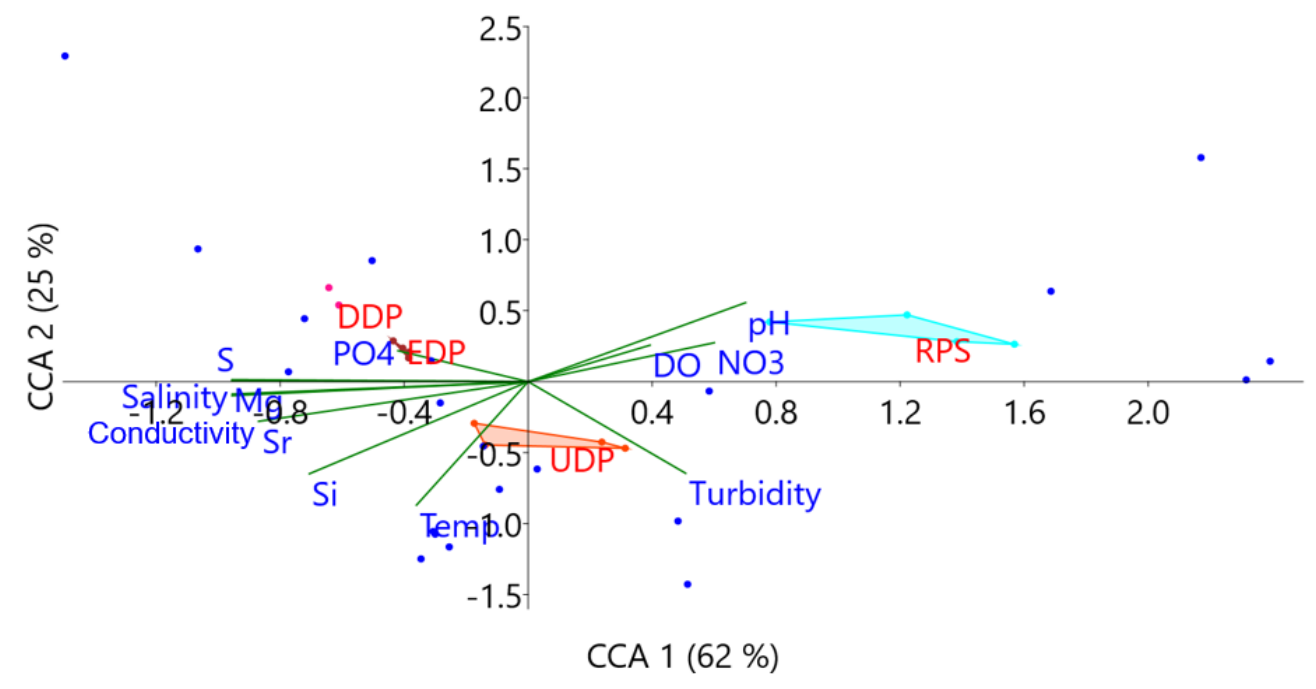




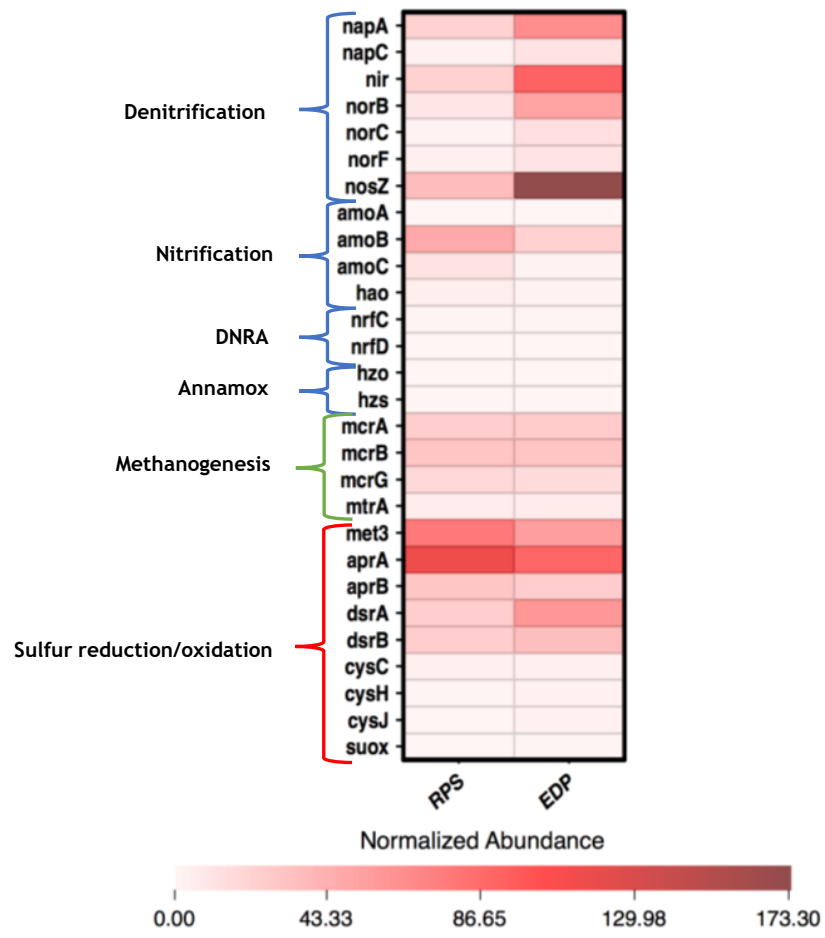



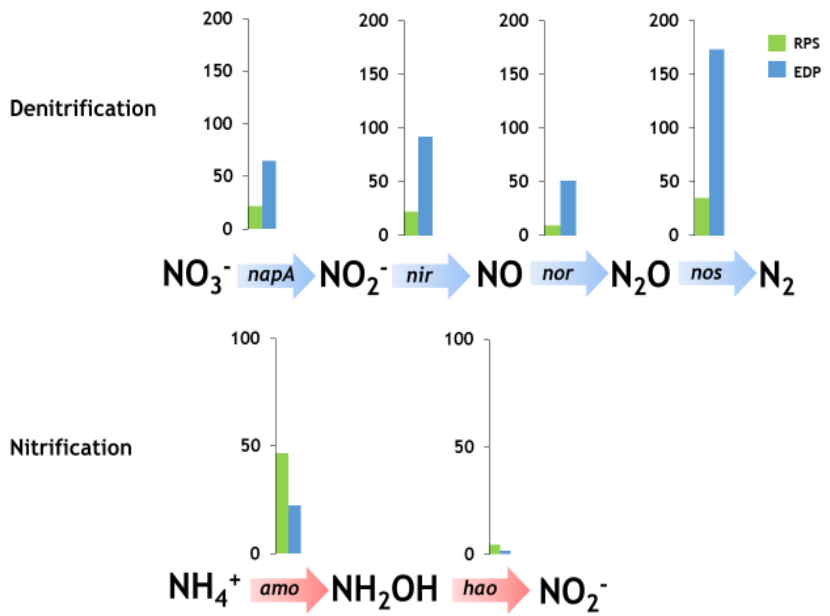


\section{HIGHLIGHTS}

- expression of nos $Z$ is influential in the wastewater treatment effluent sediments

- low nitrate indicates high nitrogen turnover in the sediments

- effluent impacted sediments appear to be significantly affected by nutrient loads 